\title{
RADIOLYSIS OF REACTIVE AZO DYES IN AQUEOUS SOLUTION
}

\author{
Agustin N.M. Bagyo, Winarti Andayani, Hendig Winarno, \\ Ermin Katrin and Yanti S. Soebianto \\ Centre for Research and Development of Isotopes and Radiation Technology, \\ National Nuclear Energy Agency, Jl Cinere Pasar Jumat PO BOX 7002 JKSKL Jakarta 12070 \\ e-mail : agustinnmb@yahoo.com
}

\begin{abstract}
RADIOLYSIS OF REACTIVE AZO DYES IN AQUEOUS SOLUTION. The effects of radiation on aerated reactive dye solutions i.e Cibacron Violet, Cibacron Orange and Cibacron Yellow solutions have been studied. Parameters analysis were the change of $\mathrm{pH}$ after radiation, the change of absorption, degradation products and effects of $\mathrm{pH}$ on the radiolysis. The uv-vis absorption of solutions were observed before and after irradiation. $\mathrm{pH}$ variation was done from $\mathrm{pHs} 3,5,7,9$ and 12. Irradiation was done at doses of $0,2,4$, 6,8 and $10 \mathrm{kGy}$ with dose rate of $5 \mathrm{kGy} / \mathrm{h}$ and was determined by a Fricke dosimeter. HPLC with UV detector was used to analyze the degradation products. Oxalic acid was the main degradation product and small amount of succinic acid was also detected.
\end{abstract}

Key words : radiolysis, radiation, dyes, reactive azo dyes

\section{INTRODUCTION}

The increase of textile industry in Indonesia gives an impact on the environment. Dye wastes from textile industry are not easily degraded by ordinary treatment processes. Radiation-induced degradation and decoloration of insoluble and soluble azo and anthraquinone dyes were studied and they were found to decolorize easily, especially in the presence of oxygen during irradiation. The results were promising, so that radiation technology should be an alternative for the treatment of the waste [1-3].

Azo dyes were easily decolored by the attack of $\mathrm{OH}$ radicals formed from the radiolysis of water and the dye molecules are degraded to the lower molecular weight compounds, finally to carbon dioxide, in the presence of oxygen.

In the presence of oxygen, the hydrogen atom reacts rapidly with oxygen, leading to the formation of the oxidizing $\mathrm{HO}_{2}$ radical.

$$
\mathrm{H}^{\bullet}+\mathrm{O}_{2} \longrightarrow \mathrm{HO}_{2}^{\bullet}
$$

Chemical oxidation of organic species in the presence of oxygen is due to the interaction of oxidizing radicals (such as $\mathrm{OH}$ and $\mathrm{HO}_{2}$ radicals) with them in the aqueous solution. 
This paper summarizes studies on radiation degradation and decoloration of reactive azo dyes in water as a model systems of textile industrial waste. The use of reactive azo dyes as a model of pollutant because the dye was commonly used as a coloring material in textile industry and difficult to remove the color from the waste.

\section{EXPERIMENTAL AND METHODS}

\section{Reagents}

Reactive azo dyes Cibacron Violet (CV), Cibacron Orange (CO) and Cibacron Golden Yellow (CGY), NaOH, $\mathrm{H}_{2} \mathrm{SO}_{4}, \mathrm{H}_{3} \mathrm{PO}_{4}$ 0,005\%, Oxalic acid, Succinic acid, Formic acid, Acetic acid, and Propionic acid.

\section{Preparation of solutions}

Dye solutions were prepared by dissolving CV, CO and CGY in pure water with a dye concentration of $50 \mathrm{ppm}$. The $500 \mathrm{ml}$ solutions were placed in a Pyrex reaction vessel $(5 \mathrm{~cm}$ dia. and $16 \mathrm{~cm}$ height). The solution in various $\mathrm{pH}$ of $3,5,7,9$ and 12 were prepared by adjusted the solution by the addition of $\mathrm{NaOH}$ or $\mathrm{H}_{2} \mathrm{SO}_{4}$.

\section{Irradiation procedures}

Irradiation was done using cobalt-60 gamma-rays at room temperature with various dose of $0,2,4,6,8$ and $10 \mathrm{kGy}$. During irradiation air was bubbled through a porous plate at the bottom of the reaction vessel. The dose rate of $5 \mathrm{kGy} / \mathrm{h}$ was determined by a Fricke dosimeter. Irradiation was also carried out in the various pHs i.e 3, 5, 7, 9 and 12 and adjusted by the addition of $\mathrm{NaOH}$ or $\mathrm{H}_{2} \mathrm{SO}_{4}$.

\section{Analysis}

The change of the spectrum was measured with a Shimadzu UV 1600 spectrophotometer. The $\mathrm{pH}$ of the solution was measured with Methrom $620 \mathrm{pH}$-meter. The degradation products were determined by using HPLC with a Biograd column and uv detector. The standard organic acids were oxalic, succinic, formic, acetic and propionic acid.

The degree of degradation of the dye was calculated from the decrease of maximum absorbance by using the following equation :

Degradation $\%=\frac{\text { Ao }-\mathrm{Ai}}{\text { Ao }} \times 100 \%$

where Ao and Ai are the absorbances before and after irradiation, respectively. 


\section{RESULTS AND DISCUSSION}

\section{Degradation products}

The structure of Cibacron Violet (CV), Cibacron Orange (CO) and Cibacron Golden Yellow (CGY) are shown in Fig 1. Cibacron Golden Yellow has the chemical index reactive orange 45 but the structure is not known due to the industrial patent (Fig 1c). Figure 2 showed that the initial solutions had different $\mathrm{pH}$ due to the their chemical structures. The decline of $\mathrm{pH}$ upon irradiation indicated that formation of acidic product, and the identified products were compared with standard acids (oxalic, succinic, formic, acetic and propionic acid). The formation of oxalic acid that could be detected as degradation products of the reactive dyes are shown from Tabel 1. Figure 3 showed an example chromatogram of reactive dyes i.e CGY radiolysis products (a) and the standard acids (b). Based on that figure, it is suggested that oxalic acids was the main radiolysis products, and small amount of succinic acid was also formed.

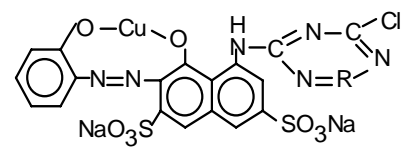

$\mathbf{a}$

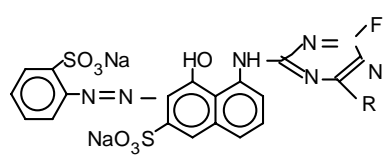

b

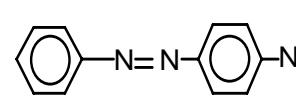

c

Figure 1. Structure molecules of Cibacron Violet (a) and Cibacron Orange (b) and Cibacron Golden Yellow (c).

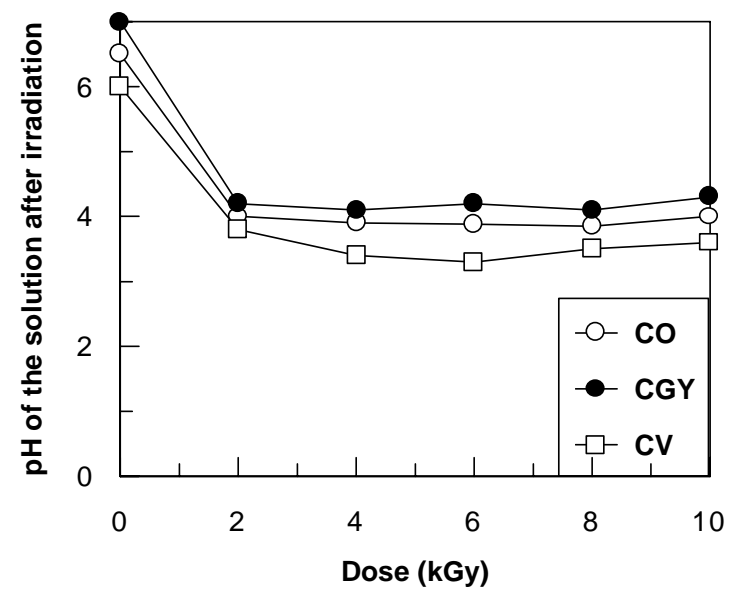

Figure 2. The change of $\mathrm{pH}$ after irradiation. 
Degradation of the dye molecules is induced by the reaction with oxidative species from the water radiolysis. The oxalic acid might be formed by the oxidation of benzene which is generated by the attack oxidative species such as hydroxyl radicals on the dye molecules (scheme 1-2 in Figure 4) [4-5]. At further oxidation oxalic acid could be change into carbondioxide and water molecules.

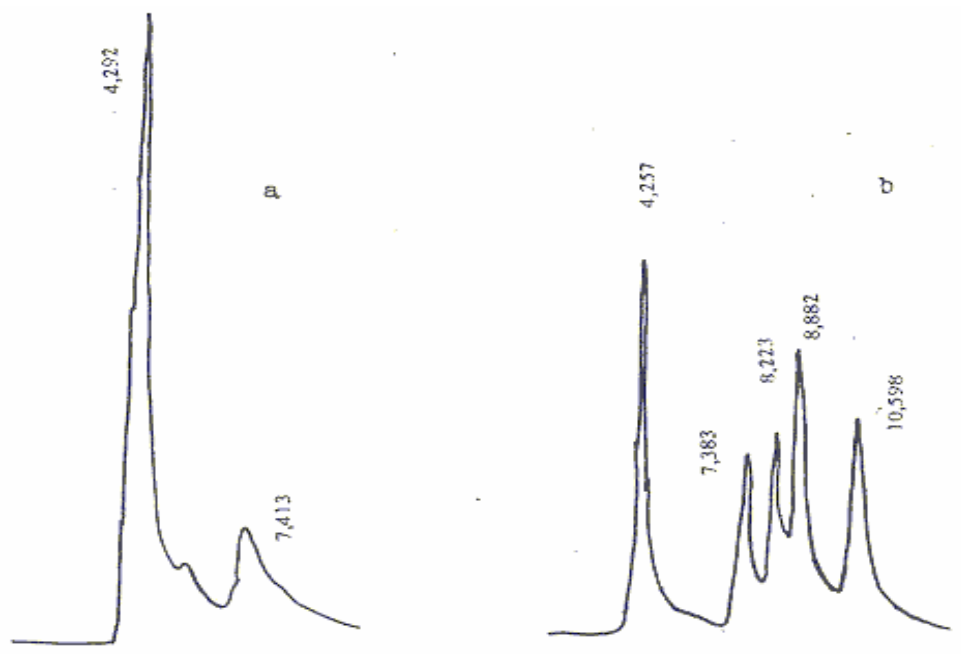

Figure 3 (a). HPLC chromatogram of irradiated CGY at dose of $10 \mathrm{kGy}$.

Figure 3 (b). Chromatogram of organic acid : oxalic acid (4,257 min), succinic acid (7,383 $\mathrm{min})$, formic acid (8,223 $\mathrm{min})$, acetic acid (8,882 $\mathrm{min})$ and propionic acid (10,598 $\mathrm{min})$.

Tabel 1. The formation of Oxalic acid from Reactive Dyes

\begin{tabular}{|c|c|c|c|}
\hline \multirow{2}{*}{$\begin{array}{c}\text { Dose } \\
(\mathrm{kGy})\end{array}$} & \multicolumn{3}{|c|}{ Oxalic Acid (ppm) } \\
\cline { 2 - 4 } & Cibacron Violet & Cibacron Orange & $\begin{array}{c}\text { Cibacron Golden } \\
\text { Yellow }\end{array}$ \\
\hline 0 & - & - & - \\
\hline 2 & 0.03 & 42.8 & - \\
\hline 4 & 0.04 & 40.6 & 2.6 \\
\hline 6 & 0.02 & 36.8 & 9.3 \\
\hline 8 & 0.01 & 36.2 & 6.4 \\
\hline 10 & 0.01 & 25.6 & 0.2 \\
\hline
\end{tabular}




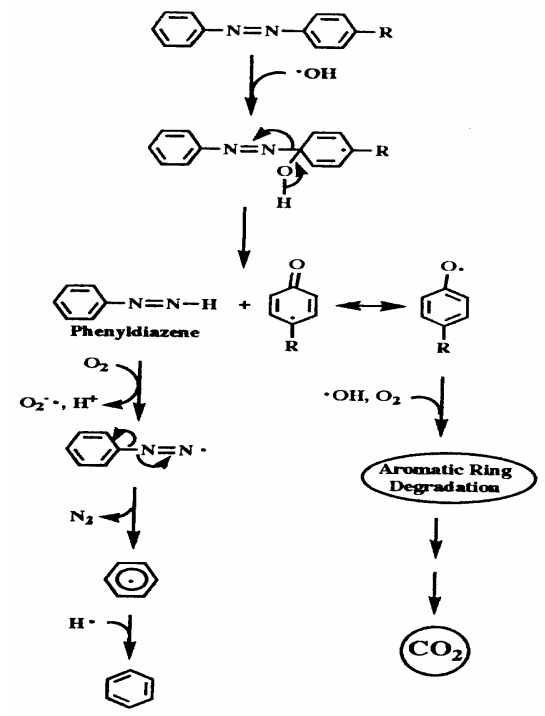

Scheme 1

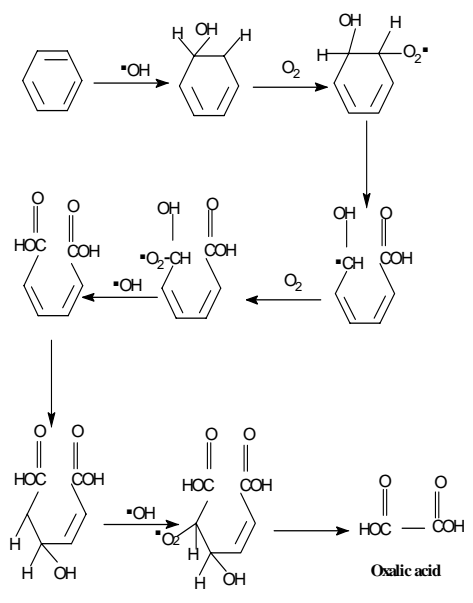

Sheme 2

Figure 4. Mechanism degradation of azo dye.

\section{Effect of $\mathrm{pH}$ on the radiolysis of reactive azo dyes}

The degradation at different $\mathrm{pH}$ values for some reactive dyes (CGY, $\mathrm{CV}$ and $\mathrm{CO}$ ) was studied by irradiating different aqueous dye solution to a dose of $0,2,4,6,8,10 \mathrm{kGy}$. The dependence of the degradation process on $\mathrm{pH}$ is shown in Fig. 5a, b, c, d, e, respectively. It can be seen that CGY and $\mathrm{CV}$ dyes are degraded in the $\mathrm{pH}$ range from 3- 9 with a reduced sensitivity at high $\mathrm{pH}$. CO molecules hardly degraded at low dose but degraded completely at high dose (10 kGy). Observation behaviour of the effect of the $\mathrm{pH}$ on the degree of degradation is not quite clear. A possible explanation might be based on the acid-base properties of the $\mathrm{OH}$ radicals. In strong basic solution, the $\mathrm{OH}$ radicals dissociate to the less reactive $\mathrm{O}^{--}$radicals :

$$
{ }^{\circ} \mathrm{OH} \rightleftarrows \mathrm{H}^{+}+\mathrm{O}^{-} \quad(\mathrm{pH}=11.9)
$$

In fact the degradation scheme depends on the relative reactivity of the various species, availability of oxygen, dose, $\mathrm{pH}$ of the solution and temperature (6).

In acidic solution : $\mathrm{e}_{\mathrm{aq}}^{-}+\mathrm{H}^{+} \longrightarrow \mathrm{H}^{\bullet}, \mathrm{k}=2.3 \times 10^{10} \mathrm{~L} \mathrm{~mol}^{-1} \mathrm{~s}^{-1}$ the reducing $\mathrm{H}$ atoms are scavenged by oxygen leading to a formation of $\mathrm{HO}_{2}{ }^{\bullet}$ 
which can be involved in the degradation process. The $\mathrm{O}_{2}{ }^{-}$species are not very reactive but at $\mathrm{pH}>7$ the ${ }^{\circ} \mathrm{OH}$ radicals are the major primary attacking transients. The sharp decrease in the degradation at $\mathrm{pH}>9$ may be a result of the low reactivity of $\mathrm{O}^{\circ-}$ and $\mathrm{O}_{2}{ }^{\circ-}$ species to the attack of the dyes.

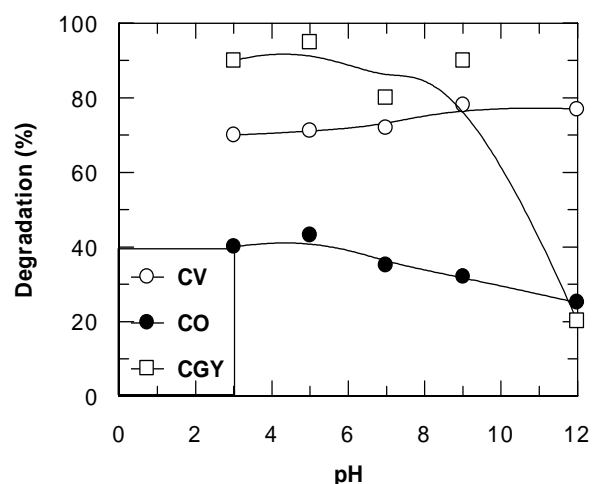

(a)

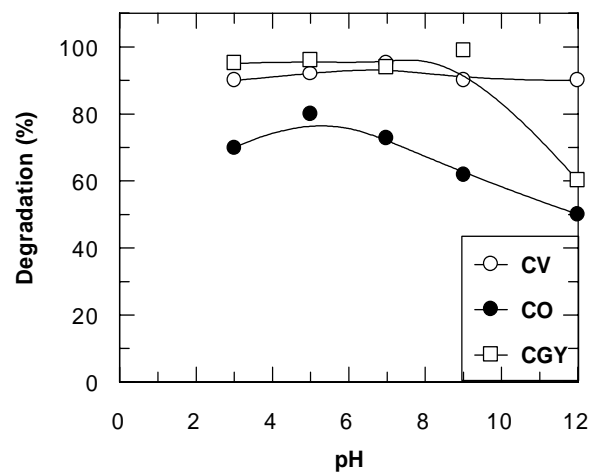

(c)

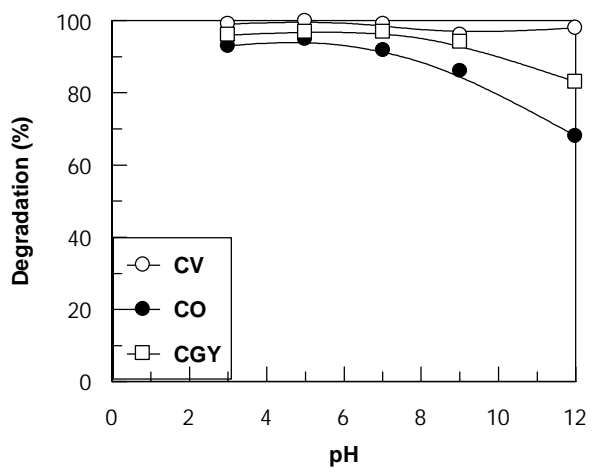

(e)

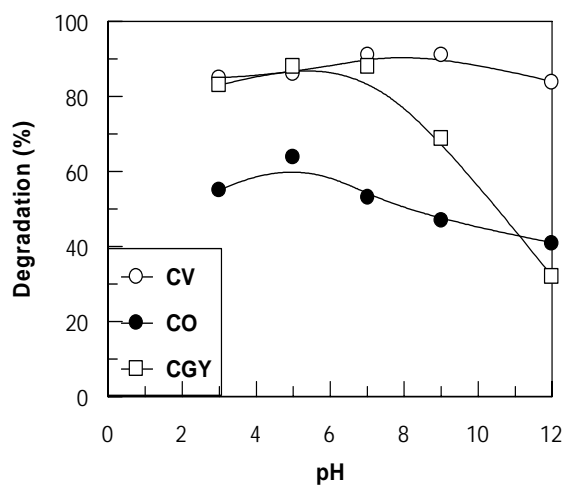

(b)

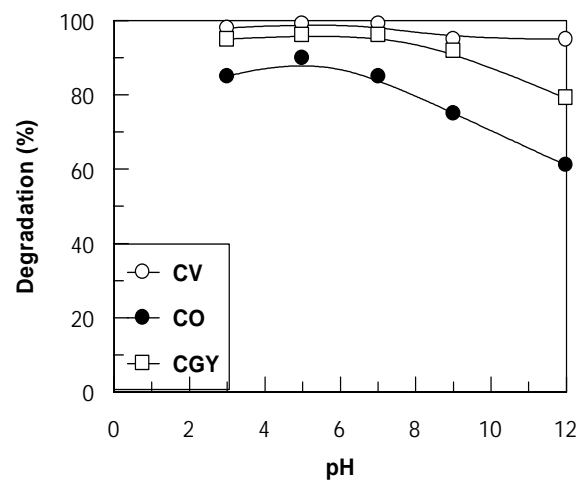

(d)

Figure 5. Effect of $\mathrm{pH}$ on the degradation of azo dyes (a) $2 \mathrm{kGy}$, (b) $4 \mathrm{kGy}$, (c) $6 \mathrm{kGy}$, (d) $8 \mathrm{kGy}$ and (e) $10 \mathrm{kGy}$. 


\section{CONCLUSIONS}

Radiation degradation of reactive dye solutions in aerated system can be carried out but the necessary dose varies with the type of the dye. Irradiation at neutral $\mathrm{pH}$ is preferred to obtain maximum degradation. Degradation products that could be dectected mainly is oxalic acid.

\section{ACKNOWLEDGEMENTS}

The authors are gratefull to Ms. Christina T.S, Mr. Syurhubel, and Mr. Armanu for their technical assistance. Thanks are also due to the member of Irradiation Facility Lab. of Centre for Research and Development of Isotopes and Radiation Technology.

\section{REFERENCES}

1. BAGYO ANM, ARAI $\mathrm{H}$ and MIYATA $\mathrm{T}$, Radiation-Induced Decoloration and Sedimentation of Colloidal Disperse Dyes in Water, Appl. Radiat. Isot. Vol 48, No.2 (1997)175-181.

2. BAGYO ANM, ANDAYANI $\mathrm{W}$ and SADJIRUN S, Radiationinduced Degradation and Decoloration of disperse dyes in water, Env. Appl. of Ionizing. Radiat. Edited by William J Cooper, Randy M Curry and Kevin O'Shea, John Wiley \& Sons Inc (1998)507.

3. HOSONO M, ARAI H, AIZAWA M, YAMAMOTO I, SHIMIZU K and SUGIYAMA M, Decoloration and Degradation of Azo Dye in Aqueous Solution Supersaturated with Oxygen by Irradiation of HighEnergy Electron Beams, Appl.Radiat.Isot., Vol. 44, No. 9 (1993) 1199-1203.

4. SPADARO JT, ISABELLE L, and RENGANATHAN V, Hydroxil Radical Mediated Degradation of Azo Dyes : Evidence for Benzene Generation. Env. Sci.Tech, Vol. 28, No. 7 (1994)1389-1393.

5. NICKELSEN M.G and COOPER WJ, Removal of Benzene and Selected Alkyl-Substituted Benzene from Aqueous Solution Utilizing Continous High Energy Irradiation, Env.Sci \& Tech, Vol 26, No 1 (1992) 144-152.

6. GETOFF N, Peroxyl Radicals (Alfassi ZB, ed) John Wiley \& Sons Ltd. (1997). 